Classification

Physics Abstracts

81.30M

\title{
A 3D study of G-phase precipitation in spinodally decomposed $\alpha$-ferrite by tomographic atom-probe analysis
}

\author{
F. Danoix, P. Auger, S. Chambreland and D. Blavette \\ Laboratoire de Microscopie Ionique, Groupe de Métallurgie Physique.- U.R.A. C.N.R.S. 808, Faculté \\ des Sciences, Place Emile Blondel, 76821 Mont Saint Aignan Cedex, France
}

(Received March 13; accepted June 14, 1994)

Résumé. - Les potentialités de la Sonde Atomique Tomographique récemment développée ont été utilisées pour étudier les précipités de phase $\mathrm{G}$ dans la ferrite d'aciers inoxydables austéno-ferritiques vieillis à $400^{\circ} \mathrm{C}$. Il a ainsi été possible, grâce aux reconstructions tridimensionnelles dans l'espace réel, de montrer que les particules de phase $\mathrm{G}$ se forment à l'interface entre les domaines $\alpha$ et $\alpha^{\prime}$ formés par décomposition spinodale de la solution solide ferritique. De plus, la très haute résolution spatiale de cet instrument a permis de révéler la morphologie interne complexe de ce type de précipités et d'étudier la répartition des éléments minoritaires en leur sein.

\begin{abstract}
The capabilities of the newly developed Tomographic Atom-Probe have been used to study G-phase precipitates in the ferritic phase of duplex stainless steels aged 30000 hours at $400^{\circ} \mathrm{C}$. It is shown, on three dimensional reconstructions in real space, that G-phase particles form at the interface between the domains produced by the $\mathrm{Fe}-\mathrm{Cr}$ spinodal decomposition, namely $\alpha$ (Fe-rich) and $\alpha^{\prime}$ (Cr-rich). Furthermore, thanks to the instrument very high spatial resolution, the complex internal morphology of these particles can be studied, in particular the partitioning of the various chemical species.
\end{abstract}

\section{Introduction.}

G-phase is a silicide known to precipitate in austenitic steels when irradiated at high temperature [1]. It has a fcc lattice with a parameter of $1.12 \mathrm{~nm}$. Its ideal stoichiometry, as determined by Transmission Electron Microscopy (T.E.M.) is $\mathrm{Ti}_{6} \mathrm{Ni}_{16} \mathrm{Si}_{7}$, where Fe, Mo can substitute to Ni, and $\mathrm{Cr}$ and $\mathrm{Mn}$ can substitute to Ti. It is only recently that Miller et al., reported, by means of T.E.M., Field Ion Microscopy (F.I.M.) and Atom-Probe microanalysis (A.P.), that it also precipitates in the ferritic phase of cast CF8M duplex stainless steels thermally aged at intermediate temperatures in correlation with the $\mathrm{Fe}-\mathrm{Cr}$ spinodal decomposition [2]. Particles were found to be a few nanometers in diameter and to precipitate preferentially on dislocations, and sometimes also homogeneously in the ferritic phase. Since, other workers corroborated this result for other duplex stainless steel grades [3-6]. It nevertheless appears that G-phase was observed for the first time 
in ferritic steels by ALLSOP and BROWN in 1960, even if not identified as " $G$ " but as "S"-phase [7]. The composition of this "S-phase" was estimated $\mathrm{M}_{3} \mathrm{Si}$ (where $\mathrm{M}$ is largely nickel, partially substituted with chromium, iron and manganese) in good agreement with G-phase composition.

The recent interest of G-phase precipitation in ferritic and duplex stainless steels is mainly related to its contribution to the embrittlement process of these steels used in the nuclear industry. It is now ascertain that the main source of embrittlement of these steels aged at $300-400{ }^{\circ} \mathrm{C}$ is the $\alpha / \alpha^{\prime}$ spinodal decomposition of the ferritic phase [8-10], however, very little is known on the role of G-phase particles. Their contribution to the embrittlement process is still controversial, and more work is needed to sort out this important issue [7, 11-13].

In addition, literature data on the actual composition of these particles, as well as on their number density and volume fraction, exhibit a very large scatter (see for example [2-7, 9]). The question whether this scatter is due to the analysis procedures or, alternatively, to the alloy bulk composition and thermal treatment, is still not clear. As long as this point is not worked out, the precipitation mechanism cannot be fully understood and applied for prediction to the various grades of duplex stainless steels.

This question can be partly answered thanks to the three- dimensional quantitative microanalytical capabilities of the newly developed Tomographic Atom Probe (T.A.P.) [14, 15]. Indeed, individual G-phase particles (as well as other compositional features) can be individually imaged and their composition measured without bias. In this paper, we will present the preliminary results we obtained on the size, composition, number density and internal morphology of these precipitates, as well as the partitioning of the various elements inside and outside G-phase particles. We will also consider the relationships between G-phase precipitation and the concomitant $\alpha / \alpha^{\prime}$ spinodal decomposition.

\section{Material.}

The analysed material, referred hereafter as A10, is a CF8M Mo-bearing duplex stainless steel, the chemical composition and ferrite content of which are given table I. As reported elsewhere [16], extensive mechanical tests have been performed on aged samples. Detailed T.E.M. and A.P.F.I.M. examinations were conducted in parallel [5]. For samples aged 30000 hours at $400{ }^{\circ} \mathrm{C}$, which are going to be analyzed in this paper, they revealed extensive spinodal decomposition of the ironchromium solid solution and a large amount of G-phase precipitates. These precipitates are homogeneously distributed in the ferrite matrix and have a rather uniform size. Larger particles are observed on dislocations, probably because these latter behave as short-circuits for diffusion. The modulated aspect of dark field images of these precipitates suggests a high density of crystalline defects, or of microdomains of another phase within the particles (Fig. 1). Conventional AtomProbe concentration profiles through G-phase particles confirmed this modulated aspect from a compositional point of view. Large concentration fluctuations of all elements and an anticorrelation between Mo and Mn were observed on the nanometer scale. In addition, two populations of particles with mutual rejection between $\mathrm{Mo}$ and $\mathrm{Al}$ were also observed. The Al-containing particles were about one fourth of the all detected particles [9]. These aspects made difficult to estimate an average G-phase composition, which was nevertheless tentatively calculated as shown table II. Silicon content, and $\mathrm{Fe}, \mathrm{Cr}$, Mo and $\mathrm{Mn}$ substitution to $\mathrm{Ni}$ and $\mathrm{Ti}$ are not incompatible with $\mathrm{Ti}_{6} \mathrm{Ni}_{16} \mathrm{Si}_{7}$ composition. Table II also gives an estimate of the average particle diameter, volume fraction and particles number density as measured by Atom- Probe analysis after aging 30000 hours at $400^{\circ} \mathrm{C}$. 
Table I. - Chemical composition and ferrite content of the analysed steel (as measured by electron microprobe, from [5]).

\begin{tabular}{|c|c|c|c|c|c|c|c|c|}
\hline element & $\mathrm{C}$ & $\mathrm{Si}$ & $\mathrm{Mn}$ & $\mathrm{Cr}$ & $\mathrm{Mo}$ & $\mathrm{Ni}$ & $\mathrm{Fe}$ & wt\% ferrite \\
\hline $\begin{array}{c}\text { bulk } \\
\text { composition } \\
\text { (wt\%) }\end{array}$ & 0.039 & 1.22 & 0.60 & 20.0 & 2.56 & 10 & bal & 24 \\
\hline $\begin{array}{c}\text { ferrite } \\
\text { composition } \\
\text { (wt\%) }\end{array}$ & - & 1.25 & 0.49 & 24.8 & 2.6 & 6.4 & bal & \\
\hline $\begin{array}{c}\text { ferrite } \\
\text { composition } \\
\text { (at\%) }\end{array}$ & - & 2.45 & 0.49 & 26.3 & 2.07 & 6.0 & bal & \\
\hline
\end{tabular}

Table II. - Characteristics of G-Phase precipitation after aging 30000 hours at $400^{\circ} \mathrm{C}$ (as measured from conventional Atom-Probe, from [5].

\begin{tabular}{|c|c|c|c|c|c|c|c|c|c|c|}
\hline $\mathrm{Fe}$ & $\mathrm{Cr}$ & $\mathrm{Ni}$ & $\mathrm{Si}$ & $\mathrm{Mn}$ & $\mathrm{Mo}$ & $\mathrm{C}$ & $\mathrm{Al}$ & $\begin{array}{c}\text { mean } \\
\text { particle } \\
\text { diameter }\end{array}$ & $\begin{array}{c}\text { particles } \\
\text { number } \\
\text { density }\end{array}$ & $\begin{array}{c}\text { G-phase } \\
\text { volume } \\
\text { fraction }\end{array}$ \\
\hline $\begin{array}{c}5-15 \\
\text { at\% }\end{array}$ & $\begin{array}{c}10-20 \\
\text { at\% }\end{array}$ & $\begin{array}{c}30-35 \\
\text { at } \%\end{array}$ & $\begin{array}{c}20-25 \\
\text { at\% }\end{array}$ & $\begin{array}{c}5-10 \\
\text { at\% }\end{array}$ & $\begin{array}{c}5-15 \\
\text { at\% }\end{array}$ & $\begin{array}{c}0-3 \\
\text { at } \%\end{array}$ & $\begin{array}{c}0-5 \\
\text { at } \%\end{array}$ & $\begin{array}{c}7.5 \pm 1 \\
\mathrm{~nm}\end{array}$ & $\begin{array}{c}0.5 \pm 0.1 \\
10^{15} \text { part } / \mathrm{cm}^{3}\end{array}$ & $\approx 12 \%$ \\
\hline
\end{tabular}

\section{Experimental.}

Samples of A10 duplex stainless steels were prepared for Tomographic Atom-Probe analyses in the same way as for conventional Atom-Probe analysis. To prepare F.I.M. tips, needles were electropolished using the standard two stage method used for steels. The voltage during the last stage was $7 \mathrm{~V}$. This value greatly improves the probability of preparing a specimen in the ferrite phase [9]. Conventional Atom-Probe analyses were performed at $40 \mathrm{~K}$, under a pressure of about $10^{-10}$ torr, and a pulse to standing voltage ratio of $20 \%$. Tomographic Atom-Probe analyses were carried out at $80 \mathrm{~K}$, under a vacuum of about $10^{-9}$ torr. The performances of this new instrument are elsewhere described in details [15]. The lateral resolution is less than $0.5 \mathrm{~nm}$ and the depth resolution is exactly one atomic layer. The mass resolution is that of a conventional Atom-Probe with a $1 \mathrm{GHz}$ timer, and will be discussed later. Three dimensional reconstructions of the analyzed volume were performed according to the procedures described in [15] for lateral and in [17] for depth positioning.

\section{Results.}

\section{Mass resolution.}

One of the main issues in performing quantitative analysis of so complicated (in terms of chemical composition) materials is to be able to unambiguously identify each species on the mass spectrum. 


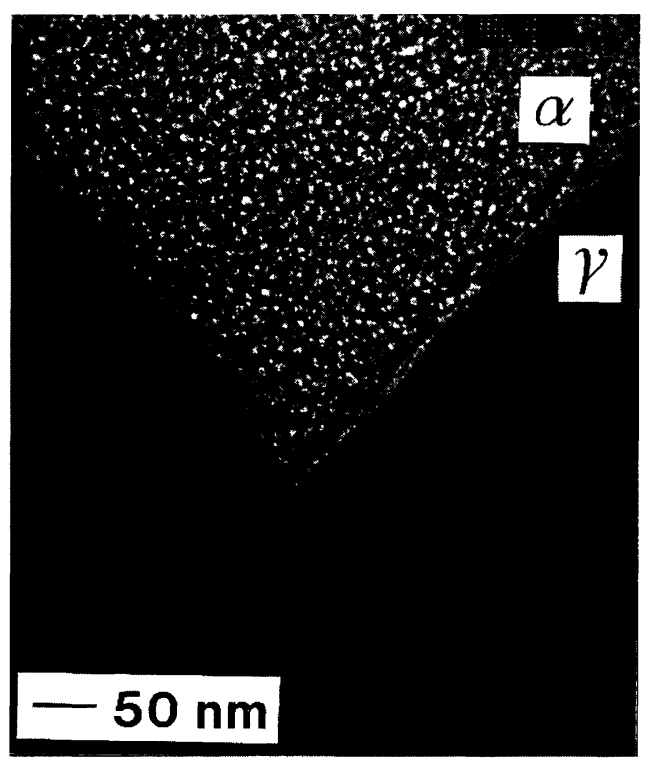

Fig. 1. - Dark field electron micrograph from $\{333\}_{\mathrm{G}}$ showing the modulated aspect of G-phase precipitates (S. Bonnet, EDF, Les Renardières).

As mentioned previously, the mass resolution of the Tomographic Atom-Probe is that of a conventional instrument with a $1 \mathrm{GHz}$ timer, i.e. $\Delta m / m \approx 1 / 200$. As shown figure 2 , this resolution is sufficient to separate most of the elements of the alloy. In particular, the peaks of $\mathrm{C}, \mathrm{Al}, \mathrm{Si}$ and $P$ are clearly separated, which allows quantitative analysis of these trace elements. This mass resolution is nevertheless not sufficient to prevent $\mathrm{Ni}^{2+}$ and $\mathrm{Mo}^{3+}$ peaks from partly overlapping. Thus, these elements are not unambiguously separated, but this effect probably does not affect more than a few percent of $\mathrm{Ni}$ and Mo atoms.

\section{Spatial distribution of solute atoms.}

Figure 3 shows the spatial distribution of solute atoms in a fraction of the analyzed volume. This basic image clearly reveals the analytical capabilities of this new instrument. All species identified on the mass spectrum are represented here, except iron. On this kind of representation, each dot represents a single atom.

$\alpha-\alpha^{\prime}$ network.

As previously observed [10], chromium atoms constitute a continuous network throughout the material volume. This network does not appear clearly on dot-type reconstructions, isosurfacetype representation is much better adapted in that case as we will see latter.

\section{G-phase particles.}

Conversely, this image clearly shows that all other species segregate in small, roughly spherical precipitates. These precipitates can easily be identified as G-phase particles. Three precipitates are distinctly separated on the represented volume. They are all mainly constituted of $\mathrm{Ni}, \mathrm{Si} \mathrm{Mo}$ and $\mathrm{Mn}$ atoms. It is also obvious that the trace elements (i.e. $\mathrm{Al}, \mathrm{C}$ and $\mathrm{P}$ ) segregate in these particles. A very interesting point concerns the relative position of the $\alpha-\alpha^{\prime}$ network and the 


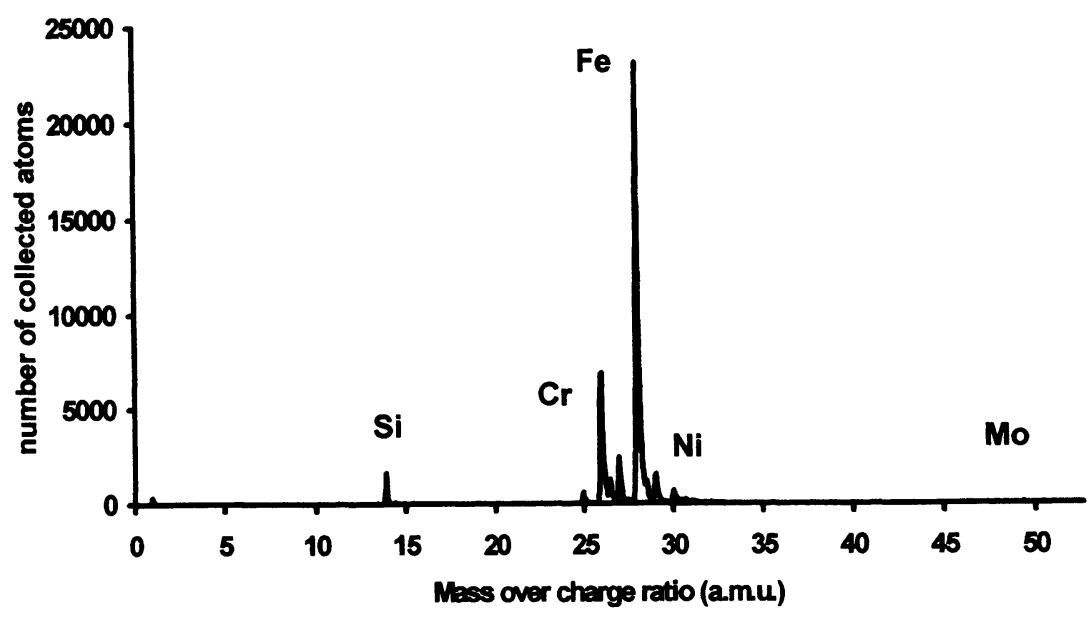

Cr-Fe-Ni

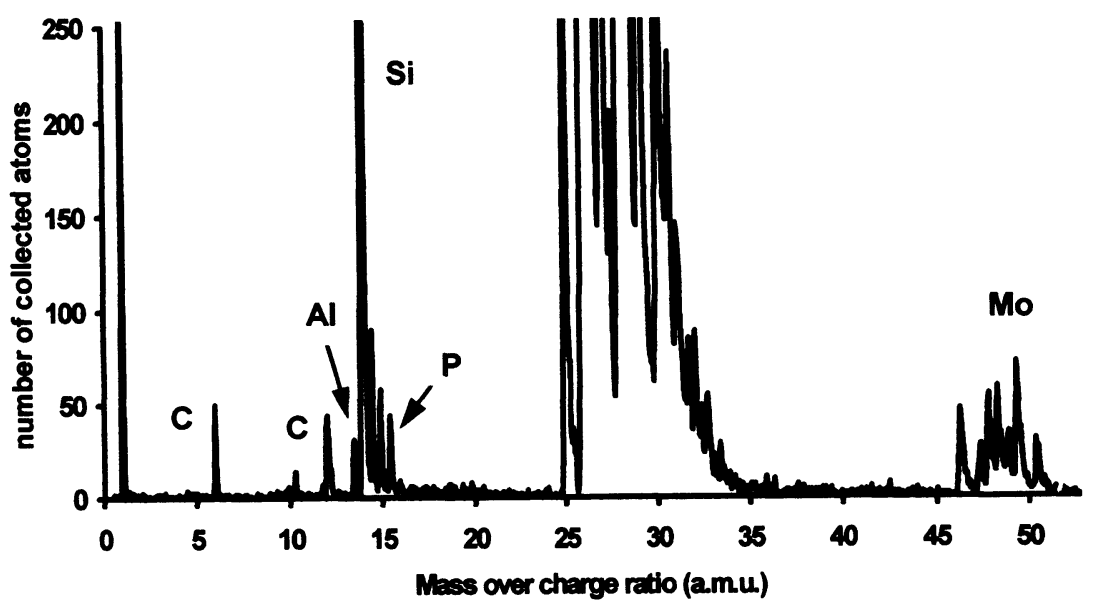

Fig. 2a and $2 \mathrm{~b}$. - Tomographic Atom-Probe mass spectra, showing that all species, including trace elements, can be unambiguously identified.

G-phase particles. Conventional atom-probe analysis strongly suggests that the particles nucleate at the $\alpha-\alpha^{\prime}$ interface. This result is confirmed by tomographic analyses, as shown figure 4 . On this figure, each G-forming element atom is represented as a single dot, and the $\alpha-\alpha^{\prime}$ network is represented by means of a surface, called an isosurface. This surface separates two types of regions characterized by a local composition respectively larger and smaller than a given threshold. The threshold value we selected (27\%at) enables to separate the $\alpha$ and $\alpha^{\prime}$ domains. The G-phase particle is clearly shown to be located at the edge of the $\alpha^{\prime}$ domain, and therefore at the $\alpha-\alpha^{\prime}$ interface. This result is in good agreement with previously published results [18], and confirms that the G-phase precipitation is related to $\mathrm{Ni}$ and $\mathrm{Si}$ rejection, respectively from $\alpha^{\prime}$ and $\alpha$, as the spinodal decomposition proceeds.

\section{Particle size, number density and composition.}

Two procedures were developed to estimate the particle diameter from $3 \mathrm{D}$ data. The first one is a simple adaptation of conventional atom-probe concentration profile. Concentration profiles are 

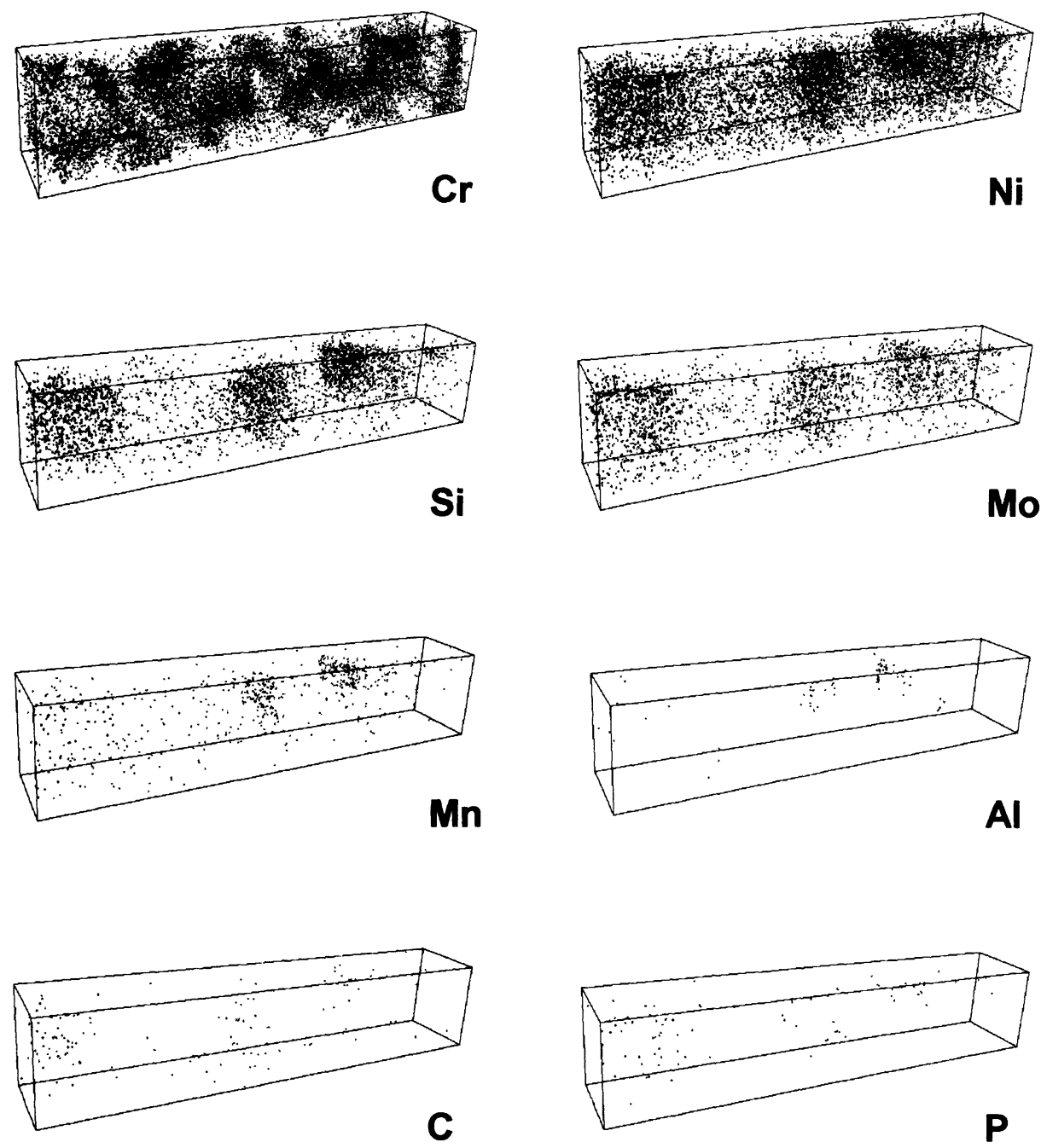

\section{$8 \times 8 \times 80 \mathrm{~nm}^{3}$}

Fig. 3. - Spatial distribution of solute atoms in the analysed volume. Each dot represents a single atom.

derived from 3D analysis by selecting a fraction of the analyzed surface, and probing perpendicular to that surface. In order to get a reliable diameter estimate, one must minimize (or at least keep constant) convolution effects between the particle and the surrounding matrix [19]. One solution is to plot a quasi-linear profile, in other words to select a very small part of the analysis crosssection. We chose a 1 by $1 \mathrm{~nm}^{2}$ unit square. Compositions are calculated over successive slices every $0.2 \mathrm{~nm}$. Concentration profiles are plotted using the moving average technique, with a window of 5 slices. The extent of the sampling volume is $1 \times 1 \times 1 \mathrm{~nm}^{3}$, and the depth increment is $0.2 \mathrm{~nm}$. The $1 \times 1 \mathrm{~nm}^{2}$ unit square is then shifted in order to overlay the whole analyzed surface. The larger distance over which a particle is intercepted is taken as its diameter. The mean diameter, calculated over the 3 particles shown figure 3 , is $9 \pm 1 \mathrm{~nm}$ (see Tab. III), which is in good agreement with previous atom-probe measurements (see Tab. II). 


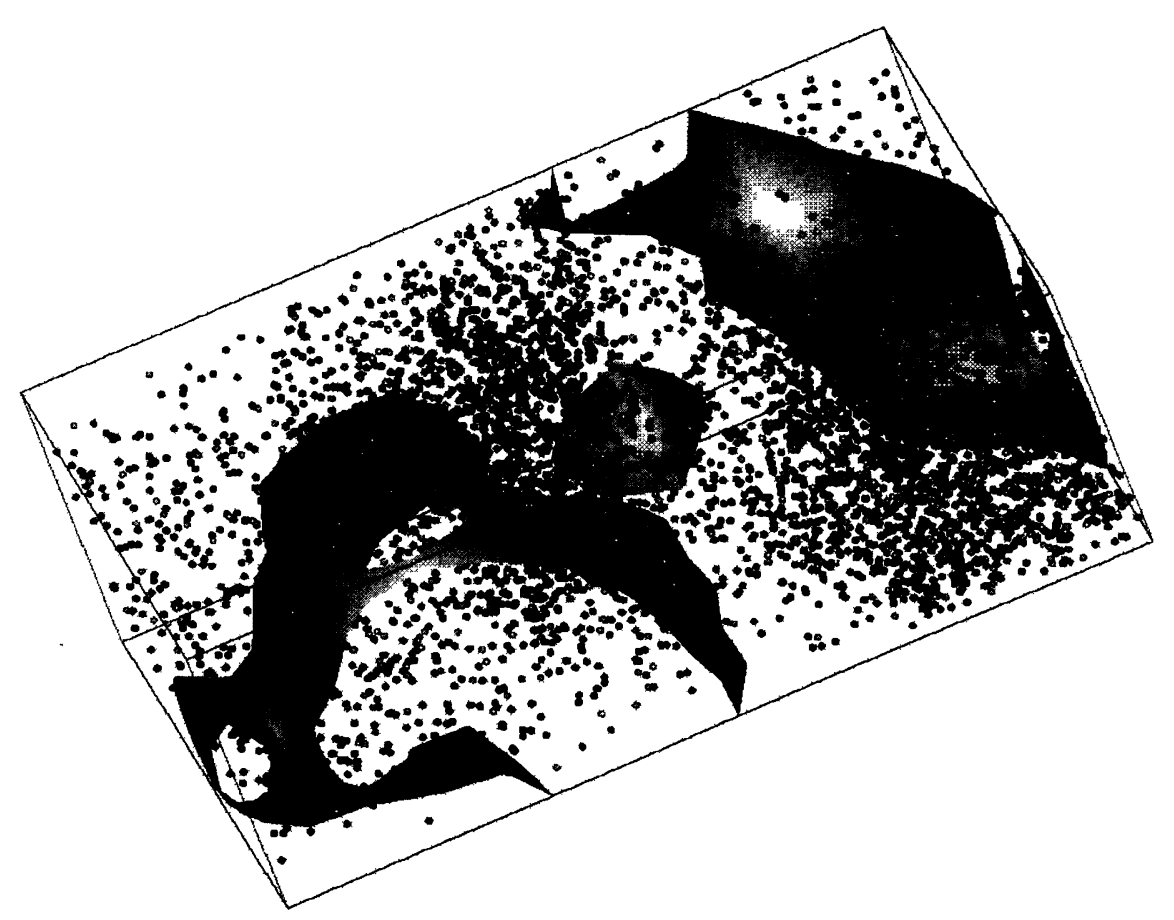

\section{$8 \times 8 \times 25 \mathrm{~nm}^{3}$}

Fig. 4. - Position of G-forming element atoms (Ni, Si, Mo, $\mathrm{Mn}, \mathrm{C}, \mathrm{Al}$ and $\mathrm{P}$, represented as dots) with respect to the $\alpha^{\prime}$ network (represented as an isosurface, threshold: 27 at \%).

Table III. - Characteristics of G-phase precipitates after aging 30000 hours at $400{ }^{\circ} \mathrm{C}$ as measured from Tomographic Atom-Probe data.

\begin{tabular}{|c|c|c|c|c|c|c|c|c|}
\hline $\mathrm{Fe}(\mathrm{at} \%)$ & $\mathrm{Cr}(\mathrm{at} \%)$ & $\mathrm{Ni}(\mathrm{at} \%)$ & $\mathrm{Si}(\mathrm{at} \%)$ & $\mathrm{Mn}(\mathrm{at} \%)$ & $\mathrm{Mo} \mathrm{(at \% )}$ & $\mathrm{C}(\mathrm{at} \%)$ & $\mathrm{Al}(\mathrm{at} \%)$ & diameter \\
\hline 15.1 & 12.3 & 33.5 & 21 & 4.3 & 11.5 & 1.3 & 0.2 & $10 \mathrm{~nm}$ \\
\pm 0.9 & \pm 0.8 & \pm 1.0 & \pm 1 & \pm 0.5 & \pm 0.8 & \pm 0.3 & \pm 0.1 & \\
\hline 10.2 & 6.1 & 28.6 & 32.7 & 6.1 & 14.3 & 2.0 & 0 & $8.5 \mathrm{~nm}$ \\
\pm 0.8 & \pm 0.6 & \pm 1.0 & \pm 1.2 & \pm 0.6 & \pm 0.9 & \pm 0.4 & & \\
\hline 10.3 & 10.9 & 34.7 & 21.9 & 4.3 & 14.5 & 1.8 & 0.3 & $10.5 \mathrm{~nm}$ \\
\pm 1.2 & \pm 1.2 & \pm 1.8 & \pm 1.6 & \pm 0.8 & \pm 1.3 & \pm 0.5 & \pm 0.2 & \\
\hline
\end{tabular}

This procedure is very simple to perform, but has a major disadvantage: it reduces the 3D tomographic analysis to a conventional atom-probe concentration profile. A new approach, based on geometrical arguments, was therefore developed in order to estimate the particle size and composition from 3D analyses. This method consists in calculating a radial, rather than linear, concentration profile. Concentrations are calculated over successive concentric spherical shells, instead of successive planar slices. The inner diameter of the shell plays the role of the $x$ position, 
whereas its thickness plays the role of the depth increment. The main advantage of this method is that all the atoms constituting the particle are taken into account in size and composition estimates. The particle radius is the distance between the origin and the matrix-particle interface. On such a profile, the interface appears as a compositional gradient. As compared to conventional atom-probe concentration profiles with the same depth scaling, the number of atoms per unit cell is much larger. The scatter on the local composition estimate is therefore much smaller, which enables the interface to be located with a better accuracy. This method should only be implemented in the case of spherical particles, and its major difficulty consists in carefully positioning the center of the shells at the center of the particle. This method has been applied to G-phase precipitates (Fig. 5). The interface does not appear so abrupt. This is probably due to the fact that G- phase particles are not spherical in fact, because they develop in a dissymetric environment (the $\alpha-\alpha^{\prime}$ interface). As a consequence, there is a transition domain over which the sampling volume (shells) is partly in the matrix and partly in the precipitate. It is therefore quite difficult to estimate a single value of the particle diameter, if ever it exists. The extent of the transition domain should more likely be regarded as a measurement of the particle asymmetry.

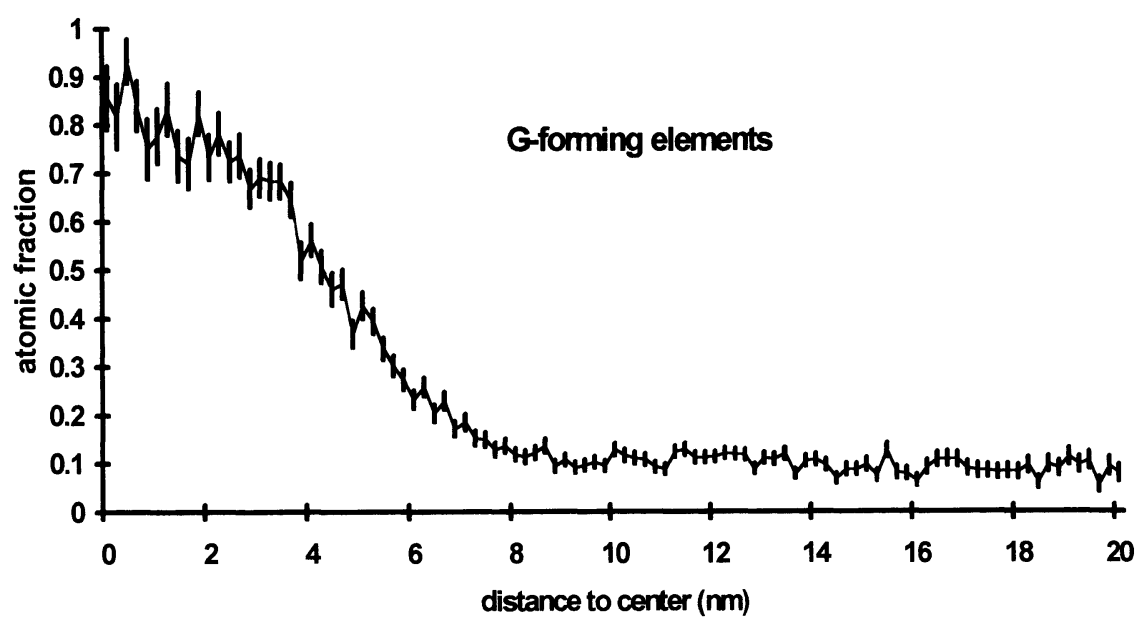

Fig. 5. - Radial concentration profile across a G-phase particle. G- forming elements are $\mathrm{Ni}, \mathrm{Si}, \mathrm{Mo}, \mathrm{Mn}$, $\mathrm{C}, \mathrm{Al}$ and $\mathrm{P}$. Vertical bars represent $\pm \sigma$, the standard deviation.

\section{G-phase particle morphology.}

One of the main advantages of tomographic analysis is that the position of each individual atom is known with a precision of a fraction of a nanometer. The distribution of the various species within each particle can therefore be analyzed in details. Figure 6 shows for example the spatial distribution of molybdenum and aluminum in the particle displayed figure 4 . Even though the particle is aluminum enriched, this representation clearly demonstrate that aluminum atoms are not homogeneously distributed. There is an Al-rich "nano-domains" on the edge of the particle. Even if it is not clear in figure 6, molybdenum has the same behavior: the particle is in average Mo-enriched, but Mo preferentially segregates in a given region of the precipitate. These heterogeneities are shown more clearly figure 7. Isosurfaces are plotted for various elements in the G-phase particle. The threshold selected for each element was chosen as half of the maximum concentration ever 
detected in the particle, in order to isolate the core of the "nano-domains". Nickel and silicon seem to be homogeneously distributed. Indeed, various thresholds were used, but none could reveal enriched regions. On the other hand, molybdenum, aluminum, but also manganese, carbon and phosphorus are shown to segregate within the particle. The first two elements reject each other, whereas manganese behaves as a link between them.

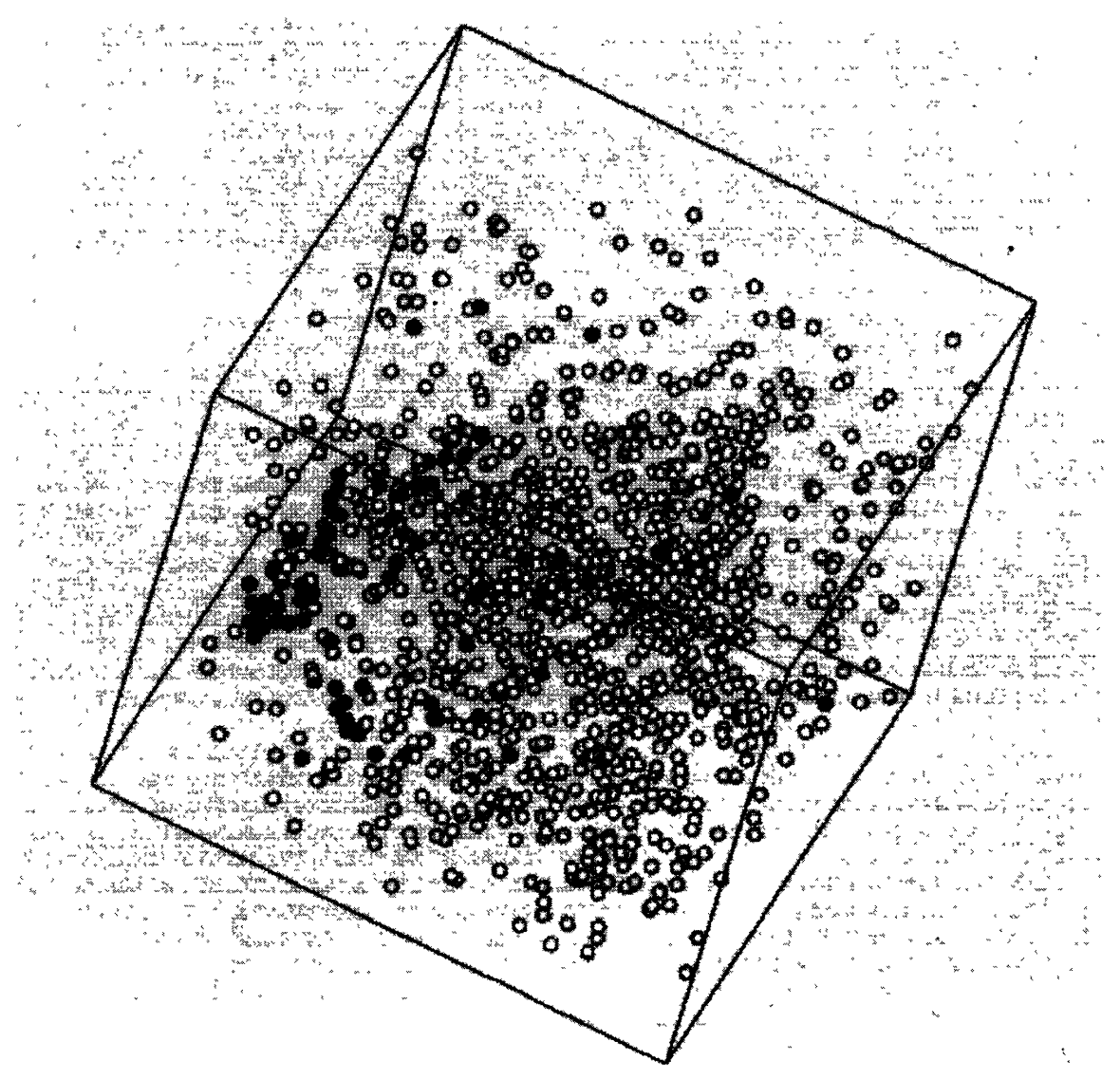

\section{$8 \times 8 \times 8 \mathrm{~nm}^{3}$}

Fig. 6. - Preferential partitioning of molybdenum and aluminum atoms within a G-phase particle $(O$ : molybdenum, : aluminum).

\section{Discussion.}

The reason why these elements have different individual behaviors is not yet understood. It nevertheless seems that it could be related to the proximity of a $\alpha$ or $\alpha^{\prime}$ region. Indeed, molybdenum 

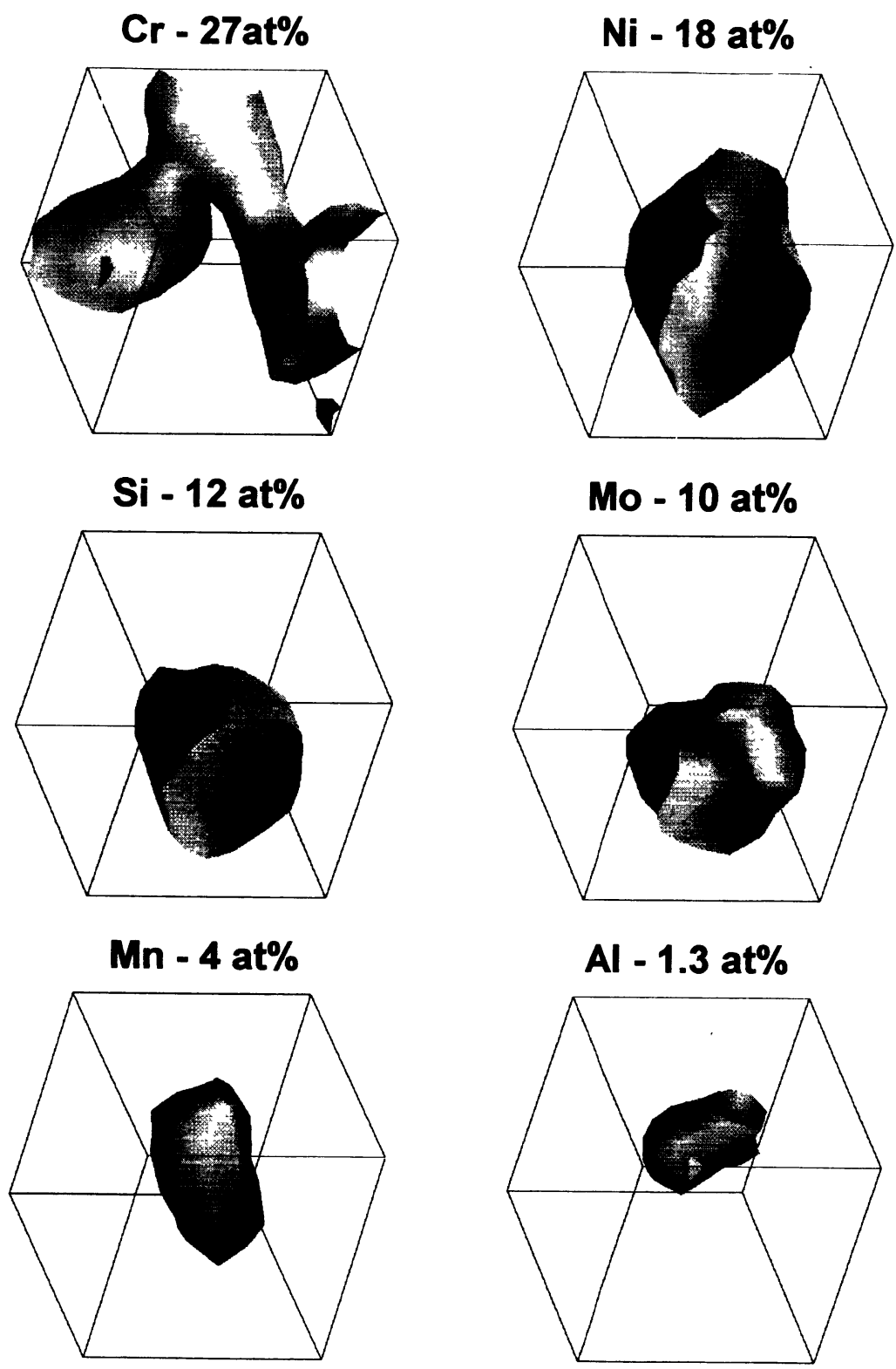

\section{$8 \times 8 \times 8 \mathrm{~nm}^{3}$ cubes}

Fig. 7. - Isosurfaces (with indicated thresholds) of various species showing the preferential partitioning within a G-phase particle (same particle as in Fig. 6, with a different orientation).

and carbon are preferentially located on the $\alpha^{\prime}$ side of the particles, whereas aluminum is preferentially situated on the $\alpha$ side.

This complex internal morphology can explain the modulated aspect of T.E.M. dark field images of G-phase particles [5]. The various "nano-domains" probably give rise to different electron 
contrasts. In addition, some other misunderstood aspects of G-phase particles, as observed with a conventional Atom-Probe, can also be cleared up by means of 3D reconstructions:

- the mutual rejection between molybdenum and manganese. It is simply related to the fact that $\mathrm{Mo}$ and $\mathrm{Mn}$ - rich nano-domains do not merge one into another.

- the existence of a fraction of $\mathrm{Al}$ containing particles as observed by conventional Atom-Probe. $3 \mathrm{D}$ reconstructions unambiguously show that all analyzed particles are $\mathrm{Al}$ enriched, but also that in fact $\mathrm{Al}$ atoms segregate in a small portion (a few percents of the overall volume) of the particle (see Fig. 6). Conventional Atom-Probe analyses, conducted with a lateral resolution of $1 \mathrm{~nm}$, have a rather small probability of intercepting a particle through its $\mathrm{Al}$ enriched domain. This probability can be calculated by means of a simple geometrical model [19], and the observed proportion of $25 \%$ (see [18]) is in good agreement with a particle diameter of $10 \mathrm{~nm}$, a lateral resolution of $1 \mathrm{~nm}$ and a Al-rich domain occupying a volume fraction of $5 \%$.

\section{Conclusion.}

This study illustrates the new capabilities offered by the Tomographic Atom-Probe in the investigation of coupled and complex precipitation processes. As this instrument combines the aptitude of performing quantitative analyses, with a spatial resolution of less than $0.5 \mathrm{~nm}$, and 3 dimensional reconstructions on the same scale, the microstructural features of the analyzed volume can be studied in details on the nanometer scale. In the case of G-phase precipitation in duplex stainless steels, 3D images clearly show (and confirm conventional Atom-Probe analyses) that particles are located at the $\alpha-\alpha^{\prime}$ interface. The very new result concerns the internal morphology of these particles. Even if their diameter is rather small (about $10 \mathrm{~nm}$ ), nano-domains, characterized by large compositional differences, are observed for the first time within the particles in real space on a near atomic scale. The reason for which only the minor elements constituting G-phase (except $\mathrm{Ni}$ and $\mathrm{Si}$ ) attract or reject each other is not yet understood, but is probably related to their attractiveness with the two surrounding Fe-rich $(\alpha)$ and Cr-rich $\left(\alpha^{\prime}\right)$ domains.

\section{Acknowledgements.}

These researches were financially supported by EDF- département Etude des Matériaux under contract CNRS/EDF N ${ }^{\circ}$ 509-113. The authors would like to thank Dr. A. Bostel for discussion and software implementation, Drs. J.P. Massoud (EDF) and M. Guttmann (IRSID) for the helpful discussions we had during the course of this work.

\section{References}

[1] Lee E.H., Maziasz P.J. and Rowcliffe A.F., in "Phase Stability during Irradiation", J.R. Holland, L.K. Mansur and D.I. Potter Eds., TMS-AIME (Warrendale, PA, 1981) 191.

[2] Miller M.K., Bentley J., Brenner S.S. and Spitznagel J.A., J. Phys. 45-C9 (1984) 385.

[3] Vrinat M., Cozar R. and Meyzaud Y., Scripta Met. 20 (1986) 1101.

[4] Vitek J.M., Met. Trans. A 18A (1987) 154.

[5] Auger P., Danoix F., Menand A., Bonnet S., Bourgoin J. and Guttmann M., Mat. Sci. Techn. 6 (1990) 301.

[6] Chung H.M. and Leax T.R., Mat. Sci. Techn. 6 (1990) 249.

[7] Brown G.T. and Allsop R.T., J. Iron Steel Inst. (April 1960) 435. 
[8] Brenner S.S., Miller M.K. and Soffa W.A., Scripta Met. 16 (1982) 831.

[9] Danoix F., thèse de doctorat de l'Université de Rouen (1991).

[10] Brown J.E., MSc University of Oxford (1991).

[11] Chung H.M. and Chopra O.K., in "Environmental Degradation of Materials in Nuclear Power Systems - Water Reactors", G.J. Theus and J.R. Weeks Eds., The Metallurgical Society (1988) 359.

[12] Alexander D.J., Alexander K.B., Miller M.K. and Nanstad R.K., P.V.P.- Vol. 195, Fatigue, Degradation and Fracture, W.H. Bamford, C. Becht IV, S.B. Framatome, J.D. Gilman, L.A. James and M. Prager Eds., Book $\mathrm{N}^{\circ} \mathrm{H} 00614$ (1990).

[13] Vitek J.M., David S.A., Alexander D.J., Kaiser J.R. and Nanstad R.K., Acta Met. 39 (1991) 503.

[14] Blavette D., Bostel A., Sarrau J.M., Deconihout B. and Menand A., Nature 363 (1993) 432.

[15] Blavette D., Deconihout B., Bostel A., Sarrau J.M., Bouet M. and Menand A., Rev. Sci. Instr. 64 (1993) 2911.

[16] Bonnet S., Bourgoin J., Champredonde J., Guttmann D. and Guttmann M., Mat. Sci. Techn. 6 (1990) 221.

[17] Blavette D., Bostel A., Sarrau J.M. and Gallot J., Proceedings of 29th I.F.E.S., Göteborg (Sweden), H.O. Andren and H. Norden Eds. (1982) 497.

[18] Danoix F., Auger P., Blavette D., Surf. Sci. 266 (1992) 364.

[19] Blavette D., Chambreland S., J. Phys. 47-C7 (1986) 503. 